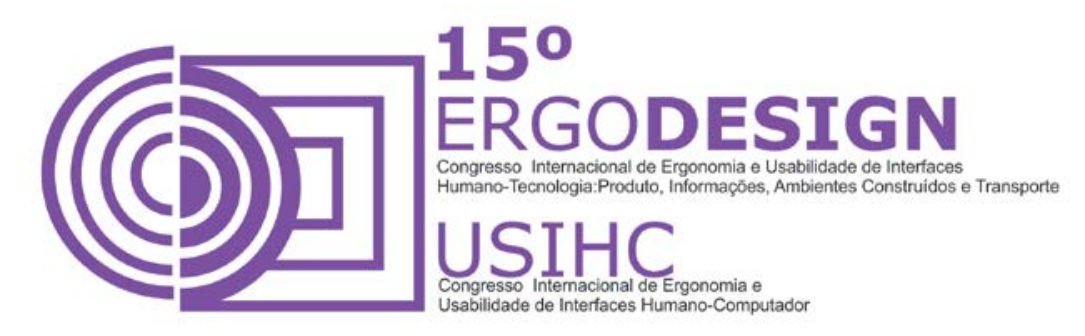

\title{
A INCLUSÃO SOCIAL POR MEIO DO DESIGN E DA ERGONOMIA: DISPOSITIVO DE INPUT DE INFORMAÇÃO PARA PESSOAS COM DEFICIÊNCIA NOS MEMBROS SUPERIORES
}

\author{
GOMES, Danila (1); \\ STAMATO, Claudia (2); \\ SANTOS, Luis Claudio Belmonte dos (3) \\ (1) Centro Universitário de Volta Redonda - UniFOA, Bacharel em Design. Pontifícia \\ Universidade Católica do Rio de Janeiro - PUC-Rio, Especialista em Ergonomia. \\ E-mail: danilagomespe@gmail.com.br \\ (2) Pontifícia Universidade Católica do Rio de Janeiro PUC-Rio, Doutora em Ergonomia. \\ E-mail: stamatoclaudia@gmail.com \\ (3) Instituto Alberto Luiz Coimbra de Pós-graduação e Pesquisa de Engenharia - \\ COPPE/UFRJ, Mestre em Engenharia de Produção. \\ E-mail: belmontedesign@gmail.com
}

\begin{abstract}
RESUMO
Este artigo apresenta o projeto de um dispositivo de input de informação que se comunica com computadores, teclado/mouse, para pessoas com malformação congênita de membros superiores. Com base no método de Gui Bonsiepe para desenvolvimento de projeto de produto, buscou-se conhecer 0 perfil dos usuários a partir da experiência vivenciada por portadores de deficiência de membros superiores com dispositivos similares, reconhecer os problemas, delimitá-los e apresentar soluções. Objetivou-se minimizar os constrangimentos psicofisiológicos, antropométricos e biomecânicos do usuário ao longo da realização da tarefa, através da oferta de usabilidade no sistema. Desta forma, estimou-se corroborar os Direitos dessas pessoas favorecendo à autonomia individual.
\end{abstract}

\begin{abstract}
This article presents the design of an input device information that communicates with computers, keyboard / mouse for people with congenital malformation of the upper limbs. Based on Gui Bonsiepe method for product design development, aimed to investigate the users profile from the experience lived by the disabled upper limb with similar devices, recognize problems, wrap them and present solutions. The objective was to minimize the psychophysiological constraints, anthropometric and biomechanical user along the accomplishment of the task, through the usability of supply in the system. Thus, it was estimated corroborate the rights of these people favoring the individual autonomy.
\end{abstract}




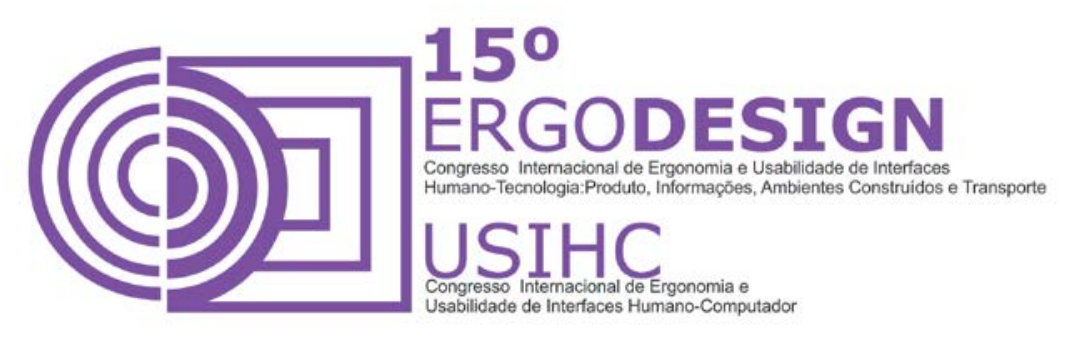

\section{INTRODUÇÃO}

O Design tem como principal objetivo solucionar problemas na relação entre produtos e usuários, serviços e clientes. Segundo o Ministério da Educação (MEC), o Desenho Industrial é classificado como uma Ciência Social Aplicada, uma área que aloja as ciências cujos conhecimentos impactam na vida humana do ponto de vista coletivo. Assim sendo, o mesmo está atrelado a outras áreas específicas do conhecimento, alongando-se de forma multidisciplinar. Seu potencial vai além da competitividade industrial: busca, também, solucionar problemas nas áreas da saúde, educação, segurança e meio ambiente.

No projeto referido buscou-se, através do design em conjunto com a ergonomia, encontrar soluções para facilitar o uso cotidiano de dispositivos, teclado e mouse, sendo estes instrumentos de trabalho, estudo ou lazer, acionados por pessoas com necessidades especiais. O embasamento teórico se deu com pesquisas sobre: malformação congênita de membros superiores, imergindo na anatomia; medicina de reabilitação; processo de inclusão social e Tecnologia Assistiva. Além de entrevistas aplicadas aos colaboradores da Associação de Assistência à Criança Deficiente (AACD), se aprofundando na terapia ocupacional e observando a vivência do público destinatário, buscando assim, conhecer a relação destes com os objetos do cotidiano.

Portanto, com base no método de Gui Bonsiepe para desenvolvimento de projeto de produto buscou-se conhecer o perfil dos usuários a partir da experiência vivenciada por portadores de deficiência de membros superiores com dispositivos similares. Este conhecimento foi fundamental para a definição de soluções específicas para os problemas estruturais, informacionais, sensório formais, de usabilidade, de produtividade e de resistência física encontrados durante a operação de dispositivos de input de informações que se comunicam com computadores em diversos ambientes.

A ergonomia como estudo das condições de trabalho, da tarefa e dos seus usuários forneceu ferramentas para estudar o melhor manuseio, bem como parâmetros de dimensionamentos ergonômicos, ângulos posturais de conforto, embasamentos para análise dos constrangimentos psicofisiológicos, antropométricos e biomecânicos sofridos pelos usuários portadores de deficiência nos membros superiores, além dos parâmetros dispostos pela ABNT. Os resultados favoreceram o desenvolvimento de artefato que possibilite a interação do usuário com o computador através do controle do mouse e do uso do teclado, atividades até então restritas ou de difícil acesso a esta população específica.

Em 2006, a Secretaria Especial dos Direitos Humanos da Presidência da República instituiu o Comitê de Ajudas Técnicas através da portaria $n^{\circ} 142$, que propõe, dentre outros objetivos, a elaboração de estudos e pesquisas relacionados aos Direitos Humanos. Portanto, pensando no direito de todos, considerando diferentes limitações, com base no Design Universal, obteve-se 


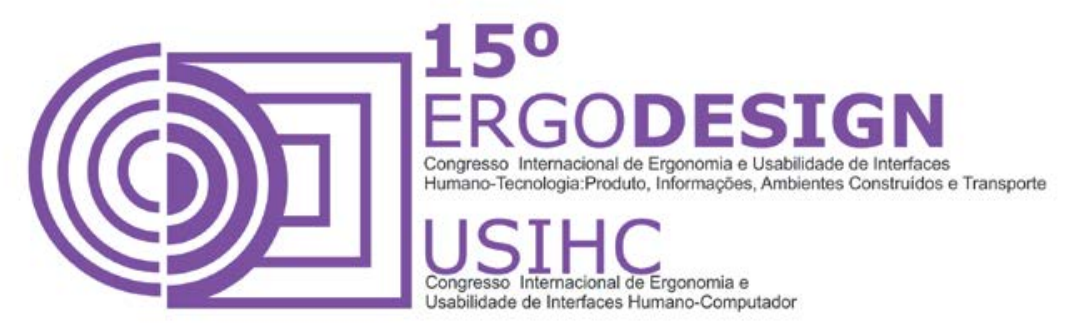

um diferencial no produto através da oferta de uma estrutura que possibilite a interação de quaisquer usuários com ou sem deficiência física dos membros superiores e usuários com deficiência visual. Na elaboração do dispositivo procurou-se transmitir em sua forma física o conforto e a praticidade, entre eles, a linguagem Braille.

\section{TECNOLOGIA ASSISTIVA}

O Design e a Ergonomia contribuem com ferramentas de pesquisa e de criação que podem ser usadas na construção de Tecnologias Assistivas. "Tecnologia Assistiva - TA é um termo utilizado para identificar todo o arsenal de recursos e serviços que contribuem para proporcionar ou ampliar habilidades funcionais de pessoas com deficiência $e$ consequentemente promover vida independente e inclusão" (BERSCH, 2008). Assim, promovem a inclusão social de pessoas com necessidades especiais oferecendo-lhes mais autonomia "através da ampliação de sua comunicação, mobilidade, controle de seu ambiente, habilidades de seu aprendizado e trabalho." (BERSCH, 2008).

A termologia usada pela Política Nacional de Saúde da Pessoa Portadora de Deficiência define Tecnologia Assistiva como um "conjunto de medidas adaptativas ou equipamentos que visam a facilitar a independência funcional das pessoas com deficiência". Sassaki vai além na definição e explicita deficiências, tipos de dispositivos e áreas de atuação: "tecnologia destinada a dar suporte (mecânico, elétrico, eletrônico, computadorizado, etc.) a pessoas com deficiência física, visual, auditiva, mental ou múltipla. Esses suportes, então, podem ser uma cadeira de rodas de todos os tipos, uma prótese, uma órtese, uma série infindável de adaptações, aparelhos e equipamentos nas mais diversas áreas de necessidade pessoal (comunicação, alimentação, mobilidade, transporte, educação, lazer, esporte, trabalho e outras." (SASSAKI, 1999).

Visando facilitar a vida de pessoas portadoras de deficiências, a TA otimiza sua funcionalidade e estruturas corporais, oportuniza a participação em atividades e oferece recursos que "podem variar de uma simples bengala a um complexo sistema computadorizado. Estão incluídos brinquedos e roupas adaptadas, computadores, softwares e hardwares especiais, que contemplam questões de acessibilidade, dispositivos para adequação da postura sentada, recursos para mobilidade manual e elétrica, equipamentos de comunicação alternativa, chaves e acionadores especiais, aparelhos de escuta assistida, auxílios visuais, materiais protéticos e milhares de outros itens confeccionados ou disponíveis comercialmente." (BERSCH e SARTORETTO, 2008). Os autores declaram ainda que os serviços de Tecnologia Assistiva são transdisciplinares envolvendo profissionais de diversas áreas, entre elas Medicina, Fisioterapia, Fonoaudiologia, Arquitetura, Engenharia e Design.

Desde 2000 o Brasil vem investindo na inclusão na educação. Na época, o número total da população era de 169.872.856 e o número de deficientes era de 24.600.250. Destes, 2.850.604 eram crianças e jovens de 0 a 17 anos. Dentro deste sub-segmento, 370.530 tinham de 0 a 4 anos, 707.763 de 5 a 9 anos, 1.083 .039 de 10 a 14 anos e 689.272 de 15 a 17 anos. Ainda entre os jovens havia outro segmento de, 18 a 24 anos, com 1.682 .760 indivíduos. (CENSO DEMOGRÁFICO, 2000). Ao longo do tempo percebeu-se uma expansão no número de deficientes físicos. 


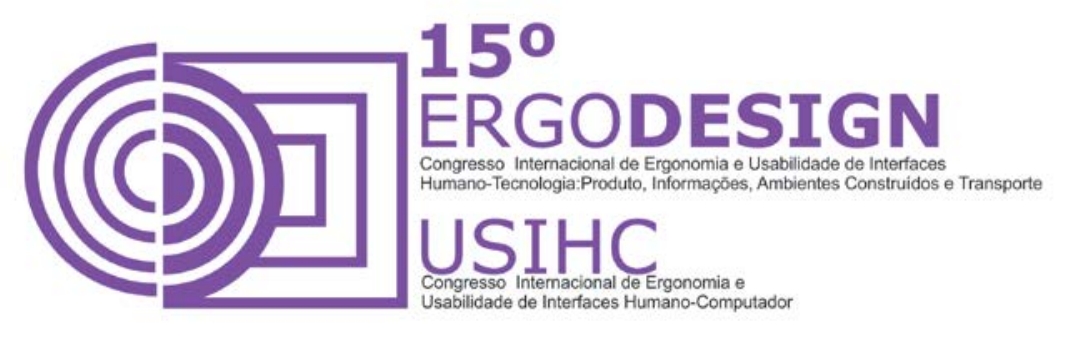

Em 2010 declararam-se portadores de pelo menos uma deficiência 45.606.048 milhões de pessoas, correspondendo a $23,9 \%$ da população brasileira. "7,5\% das crianças de 0 a 14 anos de idade apresentaram pelo menos um tipo de deficiência. A prevalência de pelo menos uma das deficiências investigadas foi maior (24,9\%) na população de 15 a 64 anos de idade e atingiu mais da metade da população de 65 anos ou mais de idade (67,7\%). Esse aumento proporcional da prevalência de deficiência em relação à idade advém das limitações do próprio fenômeno do envelhecimento, onde há uma perda gradual da acuidade visual e auditiva e da capacidade motora do indivíduo." (CENSO DEMOGRÁFICO, 2010).

Em 16 de novembro de 2006, a Secretaria Especial dos Direitos Humanos da Presidência da República (SEDH/PR), através da portaria $n^{\circ}$ 142, instituiu o Comitê de Ajudas Técnicas (CAT), a estruturar diretrizes a favor da Tecnologia Assistiva, fazendo pesquisas em vários países sobre o tema e propondo a criação de cursos na área de Tecnologia Assistiva, assim como o desenvolvimento de outras ações com o objetivo de formar recursos humanos qualificados.

\section{PROBLEMA}

\subsection{Reconhecimento do problema}

Com base no levantamento de similares realizado, foi percebido um número ínfimo de modelos de dispositivos de input de informação para pessoas com deficiência nos membros superiores. Além da insuficiência de opções, a situação se agrava devido à ausência de affordance ${ }^{1}$, o que dificulta a compreensão e uso dos dispositivos, além de gerar uma estética formal desmotivadora.

Segundo Donald Norman, "objetos atraentes fazem as pessoas se sentirem bem, o que por sua vez faz com que pensem de maneira criativa" (NORMAN, 2004). O autor enfatiza que as emoções mudam a maneira como a mente humana soluciona problemas, ou seja, a emoção interfere na operação do sistema cognitivo. Portanto, apresentar uma estética agradável, organizada e intuitiva, segundo o modelo mental do usuário é "fazer com que se torne mais fácil para as pessoas encontrar soluções para os problemas com que se deparam". (NORMAN, 2004).

Sendo assim, a estética é um desafio a ser superado na projetação de equipamento para portadores de necessidades especiais. "Os produtos e ambientes feitos com desenho acessível sinalizam que eles são destinados exclusiva ou preferencialmente para pessoas com deficiência, pois suas aparências lembram algo médico, institucional ou, em todo caso, especial. Neste sentido, eles são estigmatizantes apesar de bem-vindos." (SASSAKI, 1997).

Embora existam produtos acessíveis para esta utilização, a maioria dos usuários opta por utilizar teclados convencionais para exercer as atividades, e como esses são projetados para as mãos, possuem o dimensionamento das teclas e da estrutura inadequados para os pés. Com

${ }^{1}$ Qualidade de um objeto ou um ambiente que permite ao indivíduo realizar uma ação. 


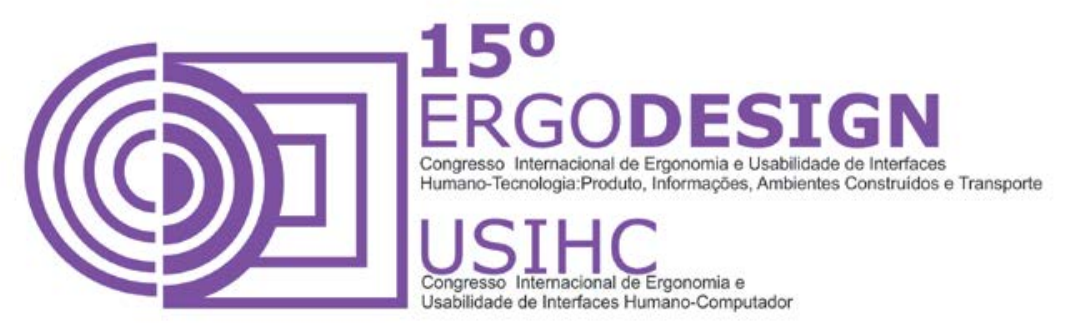

isso, esses usuários sofrem desconforto e até fadiga muscular para exercer a função.

\subsection{Delimitação do problema}

Foram identificadas quatro situações de uso. São elas: 1) Os produtos similares presentes no mercado, projetados para usuários que manuseiam objetos com os pés, mesmo com escassez, apresentam difícil entendimento e decadência estética; 2) Muitos usuários utilizam teclados convencionais para exercer as atividades. Como esses são projetados para as mãos, possuem um dimensionamento ergonômico inadequado para os pés, e sua utilização pode ocasionar desconforto e até fadiga muscular; 3) Os usuários que não possuem habilidades com os dedos dos pés fazem uso de um objeto auxiliador (exemplo: caneta e lápis) para utilizar os teclados convencionais e 4) Alguns usuários fazem adaptação nos mouses, nos teclados convencionais e no ambiente buscando facilitar a atividade.

Para delimitar o problema foram selecionados e classificados os diferentes aspectos da situação problemática entre eles: Sensório formal, Usabilidade, Produtividade, Estruturais e Moventes, Informacionais e Resistência.

Sensório formal: Entendido como a complexidade da construção de um dispositivo que tende a agregar valor à imagem do produto e agradar aos olhos do consumidor. Os formatos de dispositivos (teclado e mouse) encontrados no mercado para o grupo referido não apresentam tais qualidades, pois possuem uma aparência bruta e desconfortável.

Usabilidade: $\mathrm{Na}$ maioria dos casos, os usuários utilizam os teclados convencionais, que não apresentam dimensionamento das teclas adequado para os pés. Devido à distância entre o usuário e o artefato - que geralmente é colocado no chão enquanto o indivíduo senta-se em uma cadeira - pressupõe-se que a visualização das letras é prejudicada. Além disso, não há apoio adequado para os pés.

Produtividade: A produção do dispositivo sugerido requer moldes maiores de teclas e materiais resistentes ao impacto e ao peso. Exige-se considerar a demanda de produção baixa e a necessidade de custo final reduzido para atender à população alvo.

Estruturais e Moventes: Nos produtos encontrados não há regulagem de altura, além da dificuldade nos subsistemas e componentes de estruturação, fixação (o produto deve ter um ponto fixo para que não escorregue) e locomoção (deve ser de fácil locomoção para o usuário, caso haja a necessidade da troca do local de uso).

Informacionais: Notou-se a carência de representações positivas nos dispositivos encontrados para esse segmento. A informação deve conter funções simbólicas de maneira a favorecer uma identificação e envolvimento com os usuários. Deve ser clara, objetiva, indutora ou intuitiva, sem duplo sentido e ainda com estética agradável e motivadora aos olhos do público-alvo.

Resistências: Percebeu-se uma resistência planejada à delicadeza do uso com as mãos e não para o peso, força e movimentações dos pés. Os materiais utilizados quebram com facilidade quando usados pela população-alvo. Embora estudos apontem para uma capacidade de 


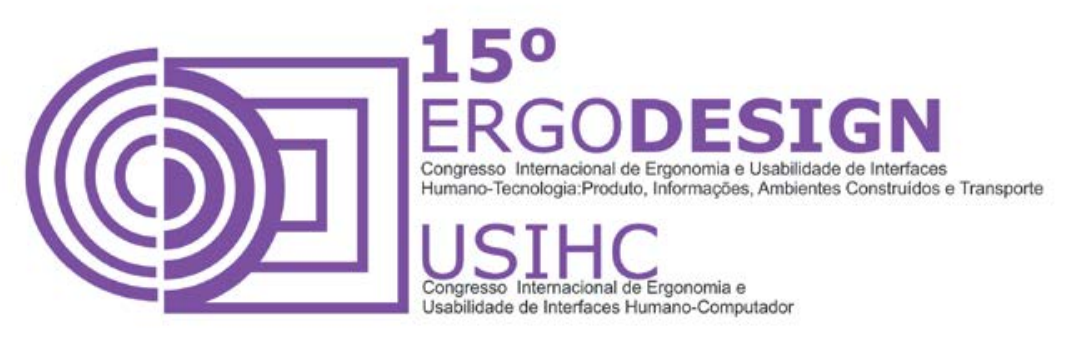

resistência desses mesmos materiais à pressão e o peso dos pés, o dimensionamento de suas paredes e espaços necessita de reforços.

\subsection{Formulação do problema}

Para maior conforto na execução da atividade: teclar e controlar o mouse através dos pés, mantendo-se sentado durante a realização da tarefa e visualizando a zona acional confortavelmente; o produto deverá ter um dimensionamento ergonômico considerando tanto a menor mulher quanto o maior homem, atendendo aproximadamente $98 \%$ da população ${ }^{2}$. Neste sentido serão consideradas as dimensões dos dedos dos pés para definição das teclas e dimensões dos calcanhares para a área de apoio dos pés, além da angulação favorável ao conforto postural dos pés e à visualização das teclas na posição de uso (pessoa sentada).

Espera-se com isso diminuir tanto o desconforto visual quanto os constrangimentos posturais no tronco e nos membros inferiores, favorecendo a redução da fadiga durante realização da tarefa. Será necessária uma altura favorável a usuários extremos para permitir maior conforto e melhor operação em função das variáveis corporais. Para melhor compreensão da informação de reconhecimento das teclas o tamanho das letras deve ser aumentado, facilitando sua visualização pelo usuário, que estará sentado e, portanto, mais distante do teclado.

O Design Universal, como solução dos estigmas oferecidos pelo design acessível, salienta que: "os produtos e ambientes feitos com desenho universal ou inclusivo não parecem ser especialmente destinados a pessoas com deficiência."(...) "É até possível que pessoas nãodeficientes nem percebam, nesses produtos ou ambientes, certas especificidades que atendem as necessidades de pessoas com deficiência." (SASSAKI, 1999).

Com base nesta afirmação o produto será destinado às pessoas com deficiência física nos membros superiores, respeitando suas limitações, necessidades e os percentis extremos, porém com uma estética não diferenciada dos demais produtos destinados aos não deficientes. A ideia é que agrade e seja aceito por todos sem estigmatizar.

\subsection{Métodos e técnicas}

Utilizou-se a revisão bibliográfica e documental a partir da discussão de diversos autores que já abordaram o tema em questão; levantaram-se dados sobre as necessidades dos usuários de hardwares informatizados, através de entrevistas semiestruturadas com profissionais da AACD; estabeleceram-se os parâmetros ergonômicos e projetuais. Além disso, desenvolveram-se modelos tridimensionais de testes e buscou-se a validação dos resultados através de testes.

\footnotetext{
${ }^{2} \mathrm{O}$ projeto se baseou nas medidas da menor mulher (1) e do maior homem (99), Embora os dados antropométricos são originados da população dos EUA, essa semelhantemente ao Brasil, "apresenta uma mistura étnica e racial mais diversa do que a de qualquer país do mundo" ( DREYFUSS, 2005.)
} 


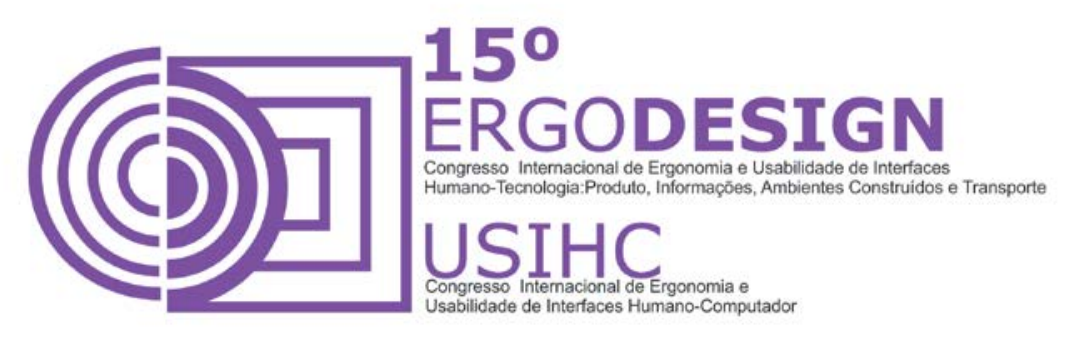

\section{DADOS ANTROPOMÉTRICOS E ERGONÔMICOS}

A respeito de dados antropométricos faz-se indispensável obter informações sobre assentos e modos de se sentar. Como o presente projeto se destina a ambientes onde há computadores, ou teoricamente ao trabalho administrativo, os dados a seguir são referentes a escritórios.

A borda frontal do assento deve ser de $125 \mathrm{~mm}$, de modo que o assento possa ter altura variável entre $370 \mathrm{~mm}$ e $495 \mathrm{~mm}$, a fim de acomodar qualquer adulto (mulher ou homem). A profundidade do assento deve ser de $406 \mathrm{~mm}$, e sua largura de $406 \mathrm{~mm}$ a $560 \mathrm{~mm}$. Ajuste de ângulo do assento: $0-15^{\circ}$, em relação à horizontal. A cadeira deve ser giratória e apresentar cinco ou seis pés, para dispor de maior estabilidade, considerando que o usuário não dispõe de membros superiores, o que pode comprometer o equilíbrio. (DREYFUSS, 2005.)

Baseando-se na pesquisa e observações feitas com os usuários, estes gostam tanto de uma postura ereta para períodos curtos quanto de uma postura relaxada que lembra um assento de automóvel para períodos mais longos. A partir dos diagramas de acionamento e controle de veículos com os pés, dados fornecidos por Dreyfuss, obtiveram-se algumas medidas de ângulos de conforto, comprimento e largura dos pés.

A ABNT NBR 9050 estabelece critérios e parâmetros técnicos a serem observados quanto às condições de acessibilidade do projeto, construção, instalação e adaptação de edificações, mobiliário, espaços e equipamentos urbanos. Portanto, este projeto baseou-se em parâmetros antropométricos, ângulos de alcance visual de letras e números e especificações na aplicação do braile sugeridas pela ABNT, em NBR 9050, e por Henry Dreyfuss Associates (2005), no livro "As medidas do homem e da mulher - Fatores Humanos em Design".

\section{Parâmetros antropométricos}

Para a determinação das dimensões referenciais foram consideradas as medidas entre os percentis 1 a 99, ou seja, os extremos correspondentes a mulheres de baixa estatura e homens de estatura elevada.

A aplicação de ângulos visuais seguiu as diretrizes estabelecidas pela ABNT 9050/94. Definiuse a distância adequada para a visualização e legibilidade das teclas e acessórios durante a realização da tarefa, na posição sentada, de $0,75 \mathrm{~m}$ a $1,00 \mathrm{~m}$ a partir dos olhos. "Informações visuais devem seguir premissas de textura, dimensionamento e contraste de cor dos textos e das figuras para que sejam perceptíveis por pessoas com baixa visão. As informações visuais podem estar associadas aos caracteres em relevo." (ABNT NBR 9050, 2004).

Entende-se que a legibilidade dos textos depende da iluminação do ambiente, do contraste e da pureza da cor, do dimensionamento das letras, do entrelinhamento e da distância entre as letras, bem como da sua forma. A ABNT assegura que: "a) Deve haver contraste entre a sinalização visual (texto ou figura e fundo) e a superfície sobre a qual ela está afixada, cuidando para que a iluminação do entorno - natural ou artificial - não prejudique a compreensão da informação. b) Os textos e figuras, bem como o fundo das peças de sinalização, devem ter acabamento fosco, evitando-se o uso de materiais brilhantes ou de alta reflexão. c) A visibilidade da combinação de cores pode ser classificada de forma decrescente em função dos 


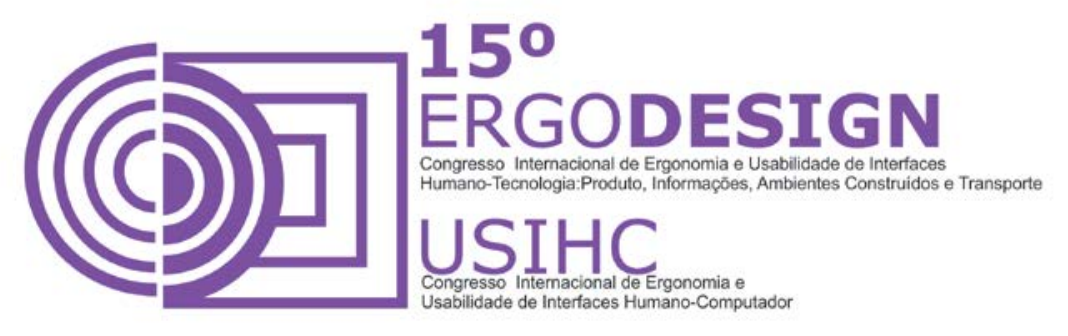

contrastes. Recomenda-se utilização de cor contrastante de $70 \%$ a 100\% (claro sobre escuro ou escuro sobre claro)." (ABNT NBR 9050, 2004).

Portanto, quando a sinalização for retroiluminada, o fundo deve ter cor contrastante, a figura e o texto devem ser translúcidos e a luz deve ser branca. E quando for necessária a adaptação a pouca luz pelo observador, deve ser utilizado texto ou figura clara sobre fundo escuro, mantendo-se o contraste.

\section{Letras e números - Dimensionamento}

A dimensão das letras e números deve ser proporcional à distância de leitura, obedecendo à relação 1/200. Recomenda-se que textos e números obedeçam às seguintes proporções: "a) largura da letra $=2 / 3$ da altura; $\boldsymbol{b}$ ) espessura do traço $=1 / 6$ da altura (caractere escuro sobre fundo claro) ou 1/7 da altura (caractere claro sobre fundo escuro); c) distância entre letras = 1/5 da altura; $\boldsymbol{d}$ ) distância entre palavras $=2 / 3$ da altura; $\boldsymbol{e}$ ) intervalo entre linhas $=1 / 5$ da altura (a parte inferior dos caracteres da linha superior deve ter uma espessura de traço distante da parte superior do caractere mais alto da linha de baixo) e f) altura da letra minúscula = 2/3 da altura da letra maiúscula." (ABNT NBR 9050, 2004).

O desenho das figuras deve atender às seguintes condições: "a) contornos fortes e bem definidos; b) simplicidade nas formas e poucos detalhes; c) forma fechada, completa, com continuidade; $\boldsymbol{d}$ ) estabilidade da forma e e) simetria." (ABNT NBR 9050, 2004).

As informações em Braille devem estar posicionadas abaixo dos caracteres ou figuras em relevo. O arranjo de seis pontos e o espaçamento entre as celas Braille deve atender às seguintes condições: "a) diâmetro do ponto na base: $2 \mathrm{~mm}$; b) espaçamento vertical e horizontal entre pontos - medido a partir do centro de um ponto até o centro do próximo ponto: $2,7 \mathrm{~mm}$; c) largura da cela Braille: 4,7 mm; d) altura da cela Braille: 7,4 $\mathrm{mm}$; e) separação horizontal entre as celas Braille: 6,6 mm; f) separação vertical entre as celas Braille: $10,8 \mathrm{~mm}$ e g) altura do ponto: 0,65 mm." (ABNT NBR 9050, 2004).

\section{CONCLUSÃO}

A partir das alternativas geradas, dividiram-se três grupos com alternativas que apresentavam características semelhantes. Após, foram levantadas as melhores ideias dentro dos grupos divididos e selecionadas as partes das alternativas que continham pontos positivos para serem aplicados ao projeto.

Foram então gerados três modelos funcionais com dimensão real (escala 1:1), cada qual com ideias e formas respectivas de seu grupo. A alternativa escolhida foi aquela cujo modelo melhor atendeu às necessidades e conforto na operação. Os modelos funcionais permitem que a decisão seja tomada com melhor precisão, pois com estes, foram feitos testes funcionais. Abaixo, os modelos testados: 

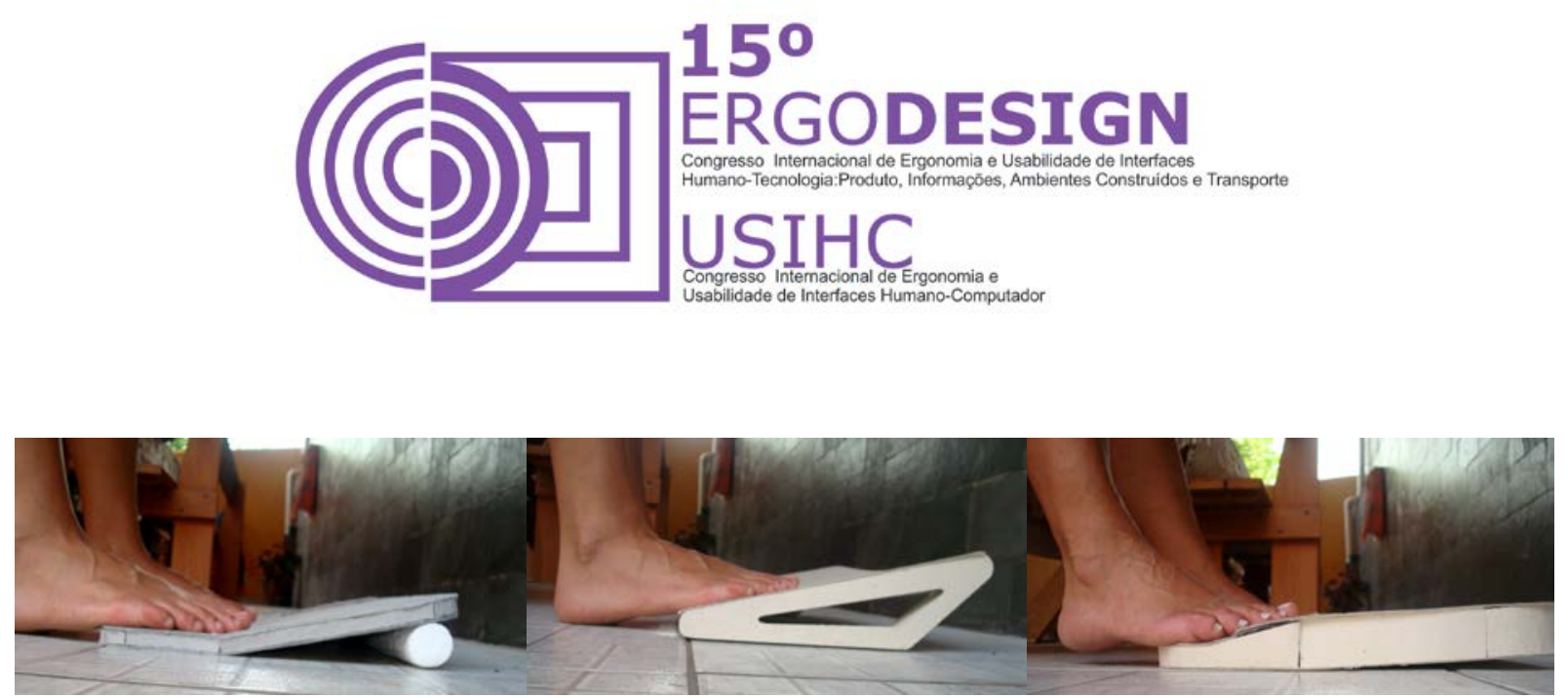

Figura 1 - Modelo funcional do Grupo A. Figura 2 - Modelo funcional do Grupo B. Figura 3 - Modelo funcional do Grupo C.

Os resultados dos testes feitos com os modelos funcionais permitem compará-los e afirmar que: a) O modelo do Grupo A (Figura 1), aproxima a visualização e o acionamento das teclas, tem estrutura leve, porém o apoio para os pés é muito baixo, necessitando de deslocamento de ângulo para a operação as teclas. b) O acionamento do modelo do Grupo B (Figura 2) é igual ao do modelo Grupo A, porém, a visualização e a operação com o movimento do pé não necessitam de uma distensão muito grande, exigindo um pequeno esforço. Faz-se necessário um apoio para descanso do pé na parte da frente e nas laterais direita e esquerda com um pequeno adoçamento de curvas na parte final. E o mouse trackball, apresentado no Modelo Grupo C, se mostrou mais funcional na operação, devendo substituir o touchpad nesta alternativa. c) $O$ modelo do Grupo C (Figura 3), possui o mouse trackball, sugerido por proporcionar mais conforto na operação, mas sua estrutura plana dificulta o acionamento e visualização das teclas, forçando o pé e dificultando a leitura das teclas.

Com o intuito de validar o produto elaborado, foram feitos testes funcionais com um modelo final, em escala real. Com isso, foi possível analisar os dimensionamentos das teclas, estrutura e acessórios, bem como observar o manuseio do produto. Os resultados foram satisfatórios, não necessitando de alterações no projeto. Abaixo, imagens ilustrando os testes feitos.

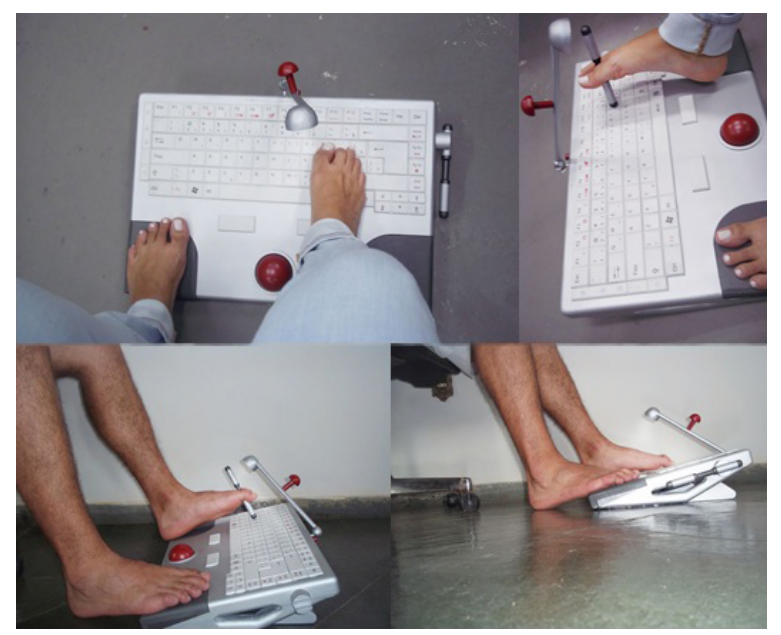

Figura 4 - Imagens dos testes funcionais com o modelo final em escala real. 


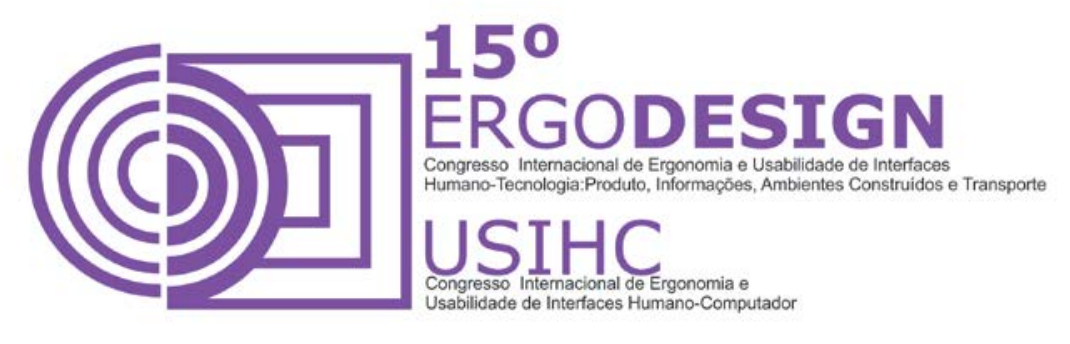

Projetado com materiais resistentes ao impacto e ao peso dos pés, o dispositivo possui o teclado selado, permitindo a higienização com mais segurança e a textura lisa para evitar acúmulo de resíduos em suas partes. Informações em Braille. Apresenta o acabamento fosco na estrutura e nas teclas, para que em contato com a luz minimize os reflexos, permitindo assim melhor visualização das partes e maior legibilidade das informações. Suas teclas foram projetadas para serem acionadas com o maior dedo do pé, conhecido como hálux (dedão do pé). Apresenta um ângulo de conforto de $10^{\circ}$, fixo em sua estrutura.

Abaixo, outras características do dispositivo:

a) Estrutura em alumínio anodizado; b) Teclas de controle do mouse separadas para maior conforto no acionamento, respeitando a área necessária para o manuseio com os pés; c) Áreas de descanso para os pés com material emborrachado e com ângulo de $10^{\circ}$, indicado como ângulo de conforto; d) Suporte de fixação (antiderrapante) ao plano de apoio; e) Conexão Bluetooth, sem a presença de fios; f) Dispositivo de Conexão de encaixe no USB com medidas ergonômicas, adequado para ser manuseado com os dedos dos pés (com o hálux e o segundo artelho); g) Caneta Auxiliadora, com as pontas antiderrapantes e área de manuseio com medidas adequadas para os dedos do pé (com o hálux e o segundo artelho), com material emborrachado; h) Mouse Trackball; i) Luminária posicionável, com movimentação de $180^{\circ}$ para as laterais, para frente e para trás e com pega ergonômica, adequada para ser acionada com os dedos do pé (com o hálux e o segundo artelho).

A partir do estudo de cores aplicáveis ao produto, respeitando a objetivo inicial do projeto que é atender tanto homens quanto mulheres, foram usadas cores neutras como o preto, o branco e o cinza e cores que apresentam contrastes, para melhor diferenciar a área de atuação, como o vermelho e o amarelo.

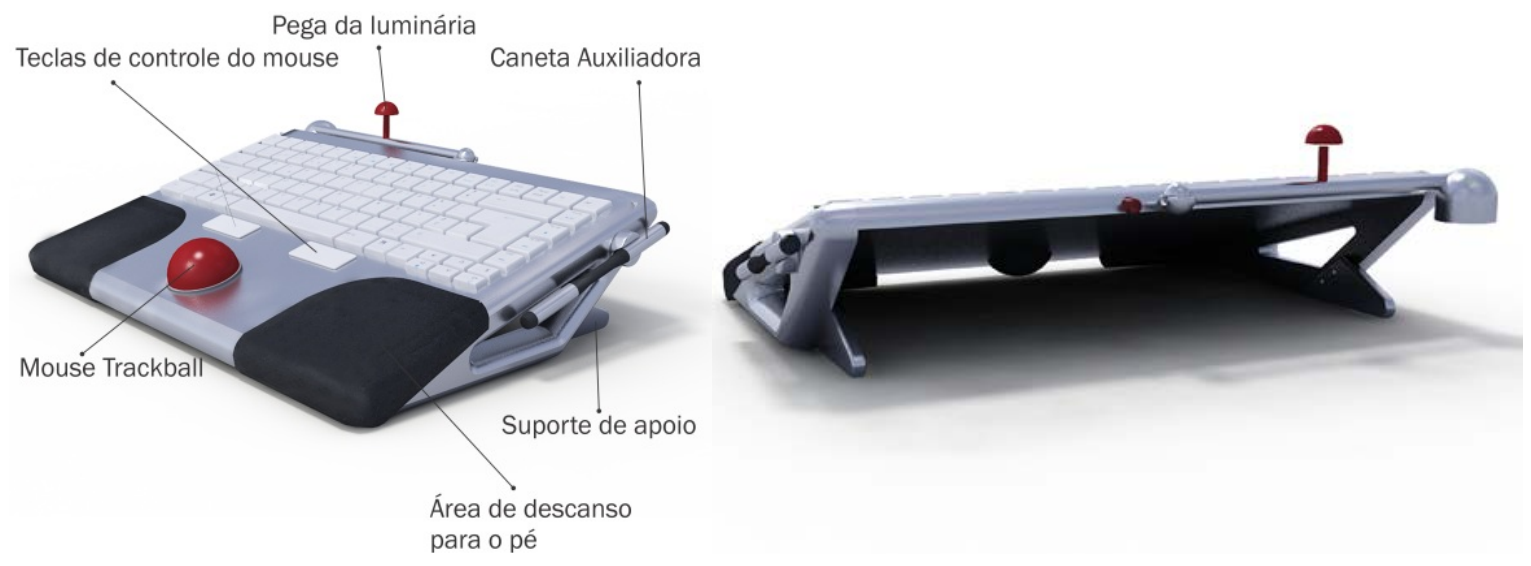

Figuras 5 e 6 - Modelo cinza. 


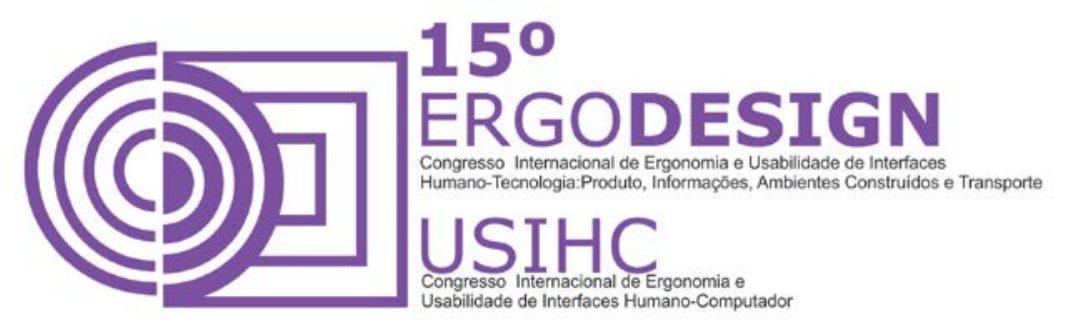

O primeiro modelo, Figuras 5 e 6, apresenta a estrutura com a própria cor do alumínio sem brilho, as teclas com um tom claro de cinza para apresentar mais contraste com as letras pretas; as áreas do descanso para os pés com um tom escuro de cinza para contrastar com a estrutura, demarcando melhor a área; as áreas de acionamento como o mouse, a pega da luminária e o botão de controle da luz em vermelho, se destacando em meio aos tons de cinza.
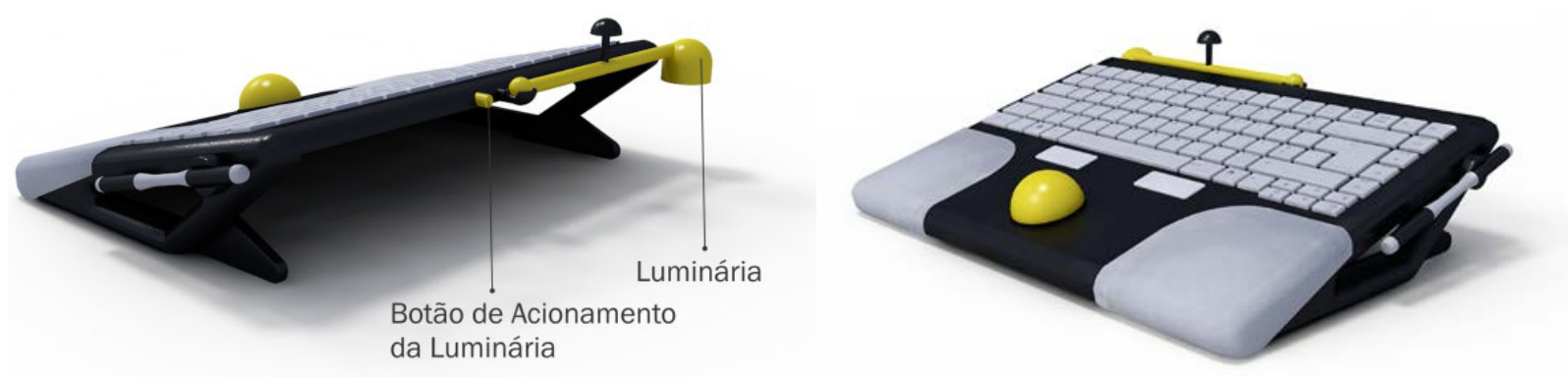

Figuras 6 e 7 - Modelo cinza.

O segundo modelo, Figuras 6 e 7, apresenta a estrutura de alumínio preta fosca contrastando com as áreas de operação; a luminária amarela, se diferenciando da estrutura; o teclado com um tom de cinza claro, para obter maior contraste com as letras pretas e oferecer mais legibilidade em contato com a luz; o mouse e o botão de acionamento da luz em amarelo para se destacarem na estrutura e as áreas de descanso para os pés bem demarcadas em um tom claro de cinza.

\section{Comentários dos voluntários dos testes:}

"Este dispositivo facilitará muito a minha vida, pois para tudo hoje precisamos utilizar o computador, para trabalhar e até para me comunicar com amigos distantes. Uso com frequência o teclado comum, sinto muitas dificuldades para teclar e dores na coluna devido à posição desconfortável que fico." (Usuário 01, voluntário dos testes).

"Ficou tudo lindo e muito funcional! Não vejo a hora desse projeto se tornar real. O mundo seria mais justo em oportunidades se houvessem projetos como este, que pensa nas pessoas que enfrentam dificuldades todos os dias." (Usuário 02, voluntário dos testes).

"Eu não tenho tanta habilidade nos dedos dos pés. Para teclar uso uma caneta ou um lápis, pois as teclas do notebook são pequenas, com as dimensões do projeto eu consegui teclar sem problemas. A caneta auxiliadora também foi uma ótima ideia para quem, mesmo com as teclas maiores, não consegue ter a habilidade para teclar." (Usuário 03, voluntário dos testes).

Diante dos ganhos na operação, notando-os na praticidade do manuseio, na facilidade do acionamento, na melhor visualização e na maior legibilidade, o aumento do conforto psíquico e físico do usuário fica em evidência: qualidades almejadas desde a concepção do projeto. Em 


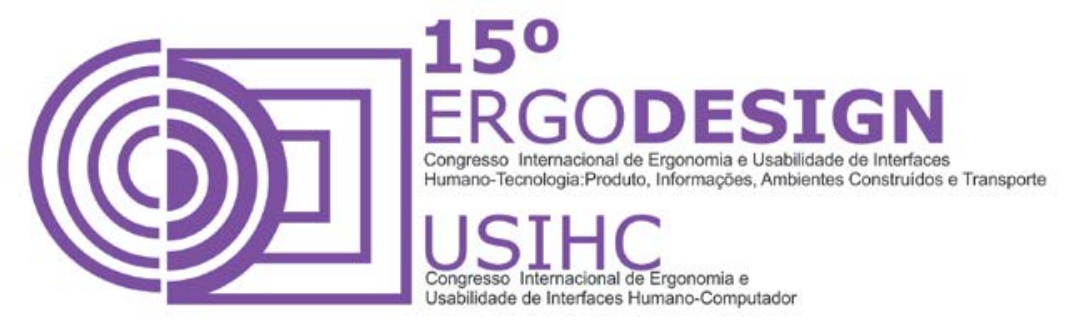

virtude das soluções propostas, espera-se contribuir com um produto que seja benéfico e auxiliador na inclusão social.

\section{REFERÊNCIAS BIBLIOGRÁFICAS}

ABNT NBR 9050:2004. 97 páginas. NORMA. BRASILEIRA. ABNT NBR. 9050. Segunda edição, 2004.

ASHKY,M.F. Materiais e design: arte e ciência da seleção de materiais no design de produto / Michael Ashby e Kara Johnson; Tradução de Arlete Símile Marques; revisão técnica de Mara Martha Roberto e Ágata Tinoco. Rio de Janeiro: Elsevier, 2011.

ASSISTIVA, O que é Tecnologia Assistiva? 2011. Anais Eletrônicos. Disponível em: <http://www.assistiva.com.br/tassistiva.html\#topo>. Acesso em: 30 de mai. 2011.

ASSOCIATES, Henry Dreyfuss / Alvin R. Tilley. As medidas do homem e da mulher - Fatores Humanos em Design. Tradução de Alexandre Salvaterra. Porto Alegre : Brookman, 2005.

BERSCH, Rita. SARTORETTO, Mara Lúcia. Centro Especializado em Desenvolvimento Infantil. Introdução a Tecnologia Assistiva. Porto Alegre, 2008. Disponível em: <http://www.assistiva.com.br/Introducao\%20TA\%20Rita\%20Bersch.pdf> Acesso em: 12 mai. 2011.

BONSIEPE, Gui. Teoría y práctica del diseño industrial - Elementos para uma manualística crítica. Colección Comunicacion Visual. Barcelona: Editorial Gustavo Gili, 1978.

BRASIL. Constituição (1985). Lei nº 7.853. Brasília, DF: Senado Federal, 1985.

BRASIL. Constituição (1989). Lei n 7.405. Brasília, DF: Senado Federal, 1989.

BRASIL. Ministério da Saúde. Política Nacional de Saúde da Pessoa Portadora de Deficiência. Brasil, 1989.

CENSO DEMOGRÁFICO 2000. Características gerais da população, religião e pessoas com deficiência. Rio de Janeiro: IBGE, 2000.

CENSO DEMOGRÁFICO 2010. Características gerais da população, religião e pessoas com deficiência. Rio de Janeiro: IBGE, 2010.

LIMA, Marco Antonio Magalhães. Introdução aos Materiais e Processos para Designers. Rio de Janeiro: Editora Ciência Moderna Ltda. 2006.

NORMAN, Donald A. Design emocional: por que adoramos (ou detestamos) os objetos do dia-a-dia. DEIRÓ, Ana (Tradutor). Rio de Janeiro: Rocco, 2008. 278 p.: il. ISBN:9788532523327. Tradução de: Emotional design : why we love (or hate) everydaythings Inclui bibliografia.

SASSAKI, Romeu Kazumi. Inclusão: Construindo uma sociedade para todos. $3^{a} e d$. Rio de Janeiro: WVA, 174p,1999.

\section{Entrevistas:}

OLIVEIRA, Sulla. Reabilitação. Entrevistadora: Danila Gomes. Nova Iguaçu, RJ: AACD, 2011. Entrevista concedida ao AACD, RJ, maio. 2011. 